\title{
Effect of Low-Level Laser Irradiation on the Function of Glycated Catalase
}

\author{
Hossein Mirmiranpour ${ }^{1}$, Fatemeh Shmas Nosrati ${ }^{2}$, Seyed Omid Sobhani ${ }^{2,3}$, Sina Nazifi Takantape ${ }^{4}$, Ahmad \\ Amjadi $^{*}$ \\ ${ }^{1}$ Endocrinology and Metabolism Research Center (EMRC), Valiasr Hospital, School of Medicine, Tehran University of \\ Medical Science, Tehran, Iran \\ ${ }^{2}$ Laser and medical Physics lab, Department of Physics, Sharif University of Technology, Tehran, Iran \\ ${ }^{3}$ Department of Energy Engineering, Sharif University of Technology, Tehran, Iran \\ ${ }^{4}$ Department of Aerospace Engineering, Sharif University of Technology, Tehran, Iran
}

\section{*Correspondence to \\ Ahmad Amjadi, PhD, Associate \\ professor, Department of Physics, \\ Sharif University of Technology, \\ Tehran, Iran. \\ Tel: +982166164521 \\ Email: amjadi@sharif.ir}

Published online 28 July 2018

\begin{abstract}
Introduction: The aim of this work is to evaluate the effect of low-level laser irradiation (LLLI), by lasers with different wavelengths, on glycated catalase enzyme in vitro experimentally.

Methods: This is done by measuring the activity and structure properties of glycated catalase enzyme. The structure properties were evaluated with circular dichroism (CD) and fluoroscopy methods. Three continuous wave (CW) lasers in the visible spectrum $(\lambda=450,530,638 \mathrm{~nm})$ and a 100 -ns pulsed laser in the infrared spectrum $(\lambda=905 \mathrm{~nm})$ were chosen for comparison. For the infrared laser, same effects have been investigated for different energy doses. The effect of photon energy (hv) at different wavelengths was measured on activity, CD, and fluoroscopy properties of catalase, and compared with the control group (samples without irradiation). The energy intensity of laser should not exceed $0.1 \mathrm{~J} / \mathrm{cm}^{2}$. Experiments were performed on glycated catalase between 2 to 16 weeks after glycation of catalase. The LLLI effect was also investigated on the samples, by comparing the catalase activity, CD and fluoroscopy for different wavelengths.

Results: Our results indicated, the decrease in catalase activity as a function of glycation time (weeks) for all samples, and a slight increase on its activity by different laser wavelengths irradiation for any fixed period of glycation time. Finally, the catalase activity has been increased as the laser's photon energy (hv) intensified. More specifically, the blue laser $(\lambda=450 \mathrm{~nm})$ had the most and the red laser $(\lambda=638 \mathrm{~nm})$ had the least effect, and the green laser $(\lambda=530 \mathrm{~nm})$ had the medium effect on catalase activity as well. Furthermore, pulsed laser had an additional effect by increasing energy dosage.

Conclusion: As we expected in all experiments, an increase in the catalase activity was coincident with a decrease in the catalase fluoroscopy and CD parameters.

Keywords: Catalase activity; Low-level laser irradiation (LLLI); Fluoroscopy.
\end{abstract}

\section{Introduction}

Catalase enzyme is responsible for intracellular regulations of $\mathrm{H}_{2} \mathrm{O}_{2}{ }^{1,2}$ and it is also a part of antioxidant defense system. ${ }^{2}$ Catalase exists in almost all human cellular microbodies but not in mitochondria. ${ }^{1}$ Diabetes mellitus accompanied by hyperglycaemia and causes enzymatic glycation of proteins such as catalase enzymes. The activity of protein is important and depends on protein structure, while glycation affects its structure and induces functional alterations. These alterations could be effective in pathogenesis of some complications of diabetes. ${ }^{3}$ Antioxidant defense deficiency and lipid metabolism disorder are the leading causes of the metabolic diseases. ${ }^{4}$ Interaction between protein and glucose, produces advanced glycated end products
(AGEs). ${ }^{5}$ AGEs could damage the protein and could have toxic effects. ${ }^{6}$ The pathologic relationship between AGEs and free radicals was shown by some prior studies. ${ }^{7}$ Some AGE compounds could be detected by fluorometry, due to their fluorescence emission properties.

Diabetes is accompanied by overproduction of free radicals, ${ }^{8,9}$ and the excessive oxidative stress. ${ }^{10}$ Consequently, the activity of antioxidant enzymes as a defensive mechanism is higher than the enzymes activity in nondiabetes condition. Catalase, as an antioxidant, could be damaged in diabetes. Moreover, free radicals, as pathogenic factors, promote the diabetic process and destroy antioxidant enzymes. ${ }^{11}$

There are various methods that are able to alter oxidative stress and the activity of catalase, such as heating and

Please cite this article as follows: Mirmiranpour H, Shmas Nosrati F, Sobhani SO, Nazifi Takantape S, Amjadi A. Effect of low-level laser irradiation on the function of glycated catalase. J Lasers Med Sci. 2018;9(3):212-218. doi:10.15171/jlms.2018.38. 
microwave radiation. ${ }^{12-14}$ In a prior study by Sallam and Awad, the effect of the static magnetic field on rat liver has been investigated. ${ }^{15}$ They exposed the whole body of rats to magnetic field for one hour each day. After 1 week, they observed that enzymatic activities were increased. Some studies showed that electromagnetic irradiation in the range of IR, visible, and ultraviolet can modify the function of enzymes. ${ }^{16}$

Fedoseyeva et al irradiated the yeast cells, by a HeNe laser with $638 \mathrm{~nm}$ wavelength ${ }^{17,18}$ and observed that the activity of catalase increased immediately after irradiation. ${ }^{18}$

Low-level laser irradiation (LLLI) was considered as an effective method to change the oxidative stress and to alter the activity of enzymes. ${ }^{19,20}$ Low-level laser therapy with $660 \mathrm{~nm}$ wavelength was also used on lung tissue to reduce the oxidative stress ${ }^{20}$ and the skin wounds in diabetic rats. ${ }^{19}$

Chen et al irradiated the seed samples with microwave radiation and HeNe laser separately, and measured the enzymatic activities. ${ }^{12}$ Later in another work, they used $635 \mathrm{~nm}$ and $808 \mathrm{~nm}$ laser irradiation on stem cells. ${ }^{21}$ They used these wavelengths separately and also as dual-wavelength laser and they concluded using both wavelengths on one sample could be more effective. ${ }^{21}$ In another study, Unnikrishna Pillai and Padma used laser irradiations with wavelengths $476 \mathrm{~nm}, 488 \mathrm{~nm}$, and 514 $\mathrm{nm}$ on seeds, and concluded that, the $476 \mathrm{~nm}$ wavelength had more effect on increasing the activity of catalase. ${ }^{22}$

Many different studies were conducted to investigate the effect of laser irradiation on parotid glands in diabetes rats. ${ }^{23-27}$ Hyperglycemia in salivary glands occurred in diabetes rates. ${ }^{24,26}$ LLLI could alter the activity of enzymes and also it effected on production of superoxide anions. ${ }^{28}$ Simoes et al used infrared diode laser on submandibular and parotid glands and measured the protein concentration and enzymatic activities. They concluded that, laser phototherapy modified the activity of catalase in diabetic rats compared to non-diabetic rats. ${ }^{24}$ They showed that, LLLI could be used as an auxiliary therapy. ${ }^{28}$ In another study, Campos et al used $780 \mathrm{~nm}$ diode laser on submandibular and sublingual rat glands, and claimed that, the activity of catalase and peroxidase was increased. ${ }^{27}$ They reported that, the laser phototherapy could be a protective mechanism against oxidative stress. In another investigation enzyme serum containing amylase was irradiated by low-level GaAlAs laser in 904 $\mathrm{nm}$ wavelength, with 0.1 to $1 \mathrm{~J} / \mathrm{cm}^{2}$ energy density. In this work, the optimum dosage for increasing the activity of catalase was obtained at $0.1 \mathrm{~J} / \mathrm{cm}^{2} .^{29}$

There remain two important questions. First, which wavelength from IR up to visible electromagnetic has the most powerful effect on catalase activity? Second, what is the advantage of continues wave (CW) laser over pulsed laser irradiation? In this article, we focus on the effect of LLLI on catalase employing different wavelength of lasers. During our experiments as recommended in a previous study, ${ }^{29}$ we kept the energy dosage of irradiations at 0.1 $\mathrm{J} / \mathrm{cm}^{2}$; At this point we repeat their experiment by three irradiation doses of $0.01,0.1$ and $1 \mathrm{~J} / \mathrm{cm}^{2}$. We observed no significant effect by irradiation at $0.01 \mathrm{~J} / \mathrm{cm}^{2}$ and damaging the sample by $1 \mathrm{~J} / \mathrm{cm}^{2}$ irradiation. Finally we found best effect of irradiation at $0.1 \mathrm{~J} / \mathrm{cm}^{2}$ which was in line with their conclusion. We chose $638 \mathrm{~nm}, 530 \mathrm{~nm}$, and $450 \mathrm{~nm}$ continues lasers in visible range, and also we chose $905 \mathrm{~nm}, 100 \mathrm{~ns}$ pulsed laser in IR range.

\section{Materials}

Catalase (C1345), glucose (G8270) and phosphate buffered saline (PBS, P5368) were acquired from Sigma Company (USA). 0.22 milliliters filter was obtained from Millipore Corporation, Billerica, MA (USA).

\section{Methods}

Glycation of catalase: The solution of the pure catalase with concentration of $10 \mathrm{mg} / \mathrm{mL}$, was made by combining this protein with phosphate buffered saline (PBS) at 7.4 $\mathrm{pH}$. A sample of pure catalase solution was prepared and named pure catalase. Then, a sample of the mentioned solution was mixed with glucose solution, with $50 \mathrm{mM} / \mathrm{L}$ concentration, and named glycated catalase. The glucose solution was prepared by combining the pure glucose with PBS. ${ }^{30-32}$

A part of solution which named glycated catalase, was directly separated and labeled as glycated control sample, but the rest of recent solution was exposed to physical factors (kind of laser) and named affected glycated sample. In other words, there were three solutions; catalase, glycated catalase, and affected glycated catalase. After filtration of all samples under sterilized condition, they were maintained in incubator at $37^{\circ} \mathrm{C}$ for 16 weeks. ${ }^{33,34}$ Every 2 weeks throughout a 16 weeks span, an aliquot of each three solutions was prepared and then saved at $-80^{\circ} \mathrm{C}$, until it could be analyzed by fluorometry, $\mathrm{CD}$ (circular dichroism), and activity assay methods. ${ }^{30-32}$ Laser Irradiation: In this study, before performing any experiment we measured absorption spectrum of samples to make sure that they had uniform absorption at different wavelengths (UV/VIS spectrometer PerkinElmer). Then we ran 2 separate series of experiments. In the first series, 3 different wavelengths of laser were used to irradiate glycated samples. The diode laser operating at $450 \mathrm{~nm}$, $530 \mathrm{~nm}$ and $638 \mathrm{~nm}$ wavelengths with $16 \mathrm{~mW}$ power, and irradiate sample for 10 minutes. Energy dose of $0.1 \mathrm{~J} /$ $\mathrm{cm}^{2}$ was achieved by adjusting the geometry of our setup at a power density of $0.17 \mathrm{~mW} / \mathrm{cm}^{2}$, during 10 minutes irradiation time (Table 1). The spot sizes of laser beams were kept constant at $94.1 \mathrm{~cm}^{2}$ during irradiation.

In the second part of experiment, a 100 ns pulsed diode laser operating at $905 \mathrm{~nm}$ wavelength, was used to irradiate the samples with four different dosages of $d=2,4,8$ and $12 \mathrm{~J} / \mathrm{cm}^{2}$. Different doses were achieved by adjusting the distance between the laser head and the sample (Table 2). 
Table 1 . Experiment Part 1: Visible Laser Irradiation Parameters

\begin{tabular}{lllllll}
\hline Laser Type & Power $(\mathbf{m W})$ & Power Density $\left(\mathbf{m W} / \mathbf{c m}^{2}\right)$ & Energy Dose $\left(\mathbf{J} / \mathbf{c m}^{2}\right)$ & Wavelength $(\mathbf{n m})$ & Irradiation Time $(\mathbf{m i n})$ & Spot Size $(\mathbf{c m})$ \\
\hline Diode (red) & 16 & 0.17 & 0.1 & 638 & 10 & 94.1 \\
Diode (green) & 16 & 0.17 & 0.1 & 530 & 10 & 94.1 \\
Diode (blue) & 16 & 0.17 & 0.1 & 450 & 10 & 94.1 \\
\hline
\end{tabular}

Table 2. Experiment Part 2: IR Laser Irradiation Parameters for 100 ns Pulsed Laser With 905 nm Wavelength

\begin{tabular}{|c|c|c|c|c|}
\hline Sample Group & Power (mW ) & Energy Dose $\left(\mathrm{J} / \mathrm{cm}^{2}\right)$ & Irradiation Time (min) & Pulse rate (pulse/s) \\
\hline D1 & 21.6 & 2 & 2.5 & 3000 \\
\hline D2 & 21.6 & 4 & 5 & 3000 \\
\hline D3 & 21.6 & 8 & 10 & 3000 \\
\hline D4 & 21.6 & 12 & 15 & 3000 \\
\hline
\end{tabular}

In the first part of the experiment, the control group did not receive any radiation. Diode lasers were driven by Main LAZMIK-01 at $450 \mathrm{~nm}$ (blue), $530 \mathrm{~nm}$ (green), and by Main 3L-TECH FARAN KLO at $638 \mathrm{~nm}$ (red), and finally by FARAN-LO7 at $905 \mathrm{~nm}$ (IR) with pulse duration $100 \mathrm{~ns} 3000$ pulse/second. To make sure that the effects were not thermal, during all our experiments, we monitored the temperature of catalase samples with IR thermo-meter for keeping the temperature at $24^{\circ} \mathrm{C}$ constantly.

Fluorometry: In this method, each of the above samples at a concentration of $0.5 \mathrm{mg} / \mathrm{mL}$ was measured by Shimadzu spectrofluorometer RF-5000 (Japan, Kyoto). Excitation and emission wavelengths of 350 and $440 \mathrm{~nm}$ were considered respectively. ${ }^{35,36}$

Circular dichroism: Spectra assessment was done by JASCO-810 spectropolarimeter (Jasco, Tokyo, Japan). The structure of each above samples containing concentration of $0.1 \mathrm{mg} / \mathrm{mL}$ was measured. The spectra were modulated and achieved as units of mean residue molar ellipticity,

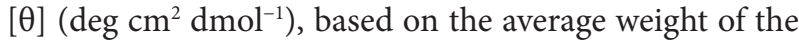
amino acids (112.4). The equation $[\theta] \lambda=(\theta \times 112.4) / \mathrm{cl}$ showed the molar ellipticity (measurements were done at $\left.25^{\circ} \mathrm{C}\right)$. $^{31,37}$

Activity: Function of catalase was measured by using the activity assay kits with enzymatic colorimetric method (Biocore Diagnosik Ulm GmbH, Germany). The measurement of the enzyme activity was performed as $\mathrm{U} /$ $\mathrm{mL}$, and the results were presented as percentage.

Error: First, we fit a curve on data points and then, we calculated the difference between data points and the fitted curve. The average deviation was considered to be an error. ${ }^{38}$

\section{Results}

Effect of irradiation on glycated catalase is presented in Figure 1. It shows that, glycated catalase activity decreases as a function of incubation time (weeks) for all control and irradiated samples. It also indicates that catalase activity increases as irradiated by red, green, and blue lasers

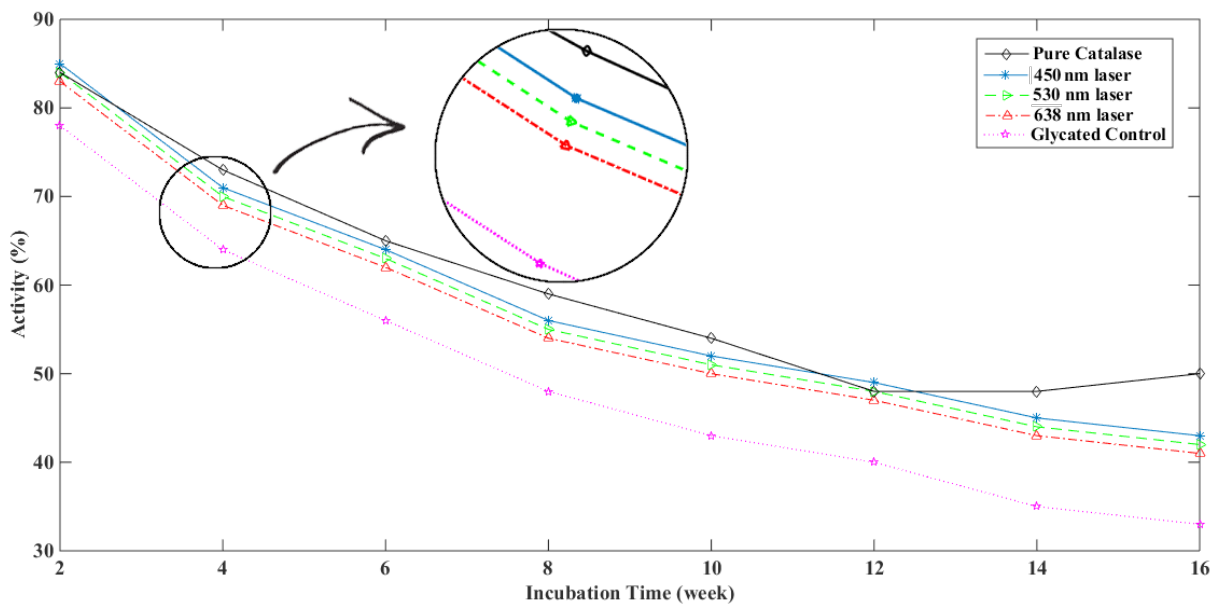

Figure 1. Catalase Activity Versus Its Incubation Time (Weeks) for Different Laser Irradiation. Red, green, blue lines are the glycated catalase samples exposed to red $(638 \mathrm{~nm})$, green $(530 \mathrm{~nm})$ and blue $(450 \mathrm{~nm})$ laser irradiation, at $0.1 \mathrm{~J} / \mathrm{cm}^{2}$ energy dose. Control groups are the glycated catalase samples which didn't receive any irradiation. Pure catalase samples were not glycated and didn't receive any irradiation (error $<0.06$ ). The error is calculated by curve fitting and measuring mean deviation. ${ }^{38}$ 
respectively with constant irradiation energy dosage of $0.1 \mathrm{~J} / \mathrm{cm}^{2}$. In this figure, the black line represents the change in the activity of pure catalase during 16 weeks. As it can be seen, for same dose of energy, the activity of glycated catalase affected by blue laser is closer to pure catalase compared to green and red lasers. This result indicates that, the activity of catalase is decreased by glycation and also the time of glycation (week). Then its activity increases by $0.1 \mathrm{~J} / \mathrm{cm}^{2}$ irradiation, blue irradiation has a maximum activity, green and red have medium and minimum activity respectively.

Figure 2 illustrates the fluorescence emission as a function of incubation time for all pure catalase, for both control and irradiated glycated catalase samples. It also indicates that, fluorescence of catalase slightly decreased, by irradiation in comparison to the control sample. Moreover, the strength of this effect is proportional to the photon energy (hv). This means that, the change of fluorescence emission induced by blue laser irradiation is higher.

Figure 3 is the plot of the $\mathrm{CD}$ ellipticity $[\theta]$ as a function of glycation time (weeks) for a pure catalase, also control and irradiated glycated catalase samples. The interpretation of this graph is very similar to its fluorescence behavior, but the effect of irradiation is lower.

Figure 4a shows, the catalase activity, as a function of glycation time (weeks). The effect of IR laser irradiation is correlated with visible laser irradiation on catalase activity. Figure $4 \mathrm{~b}$ is a cross section of Figure $4 \mathrm{a}$, at sixth week, which indicates an increase on catalase activity as the laser irradiation energy dose is increased. Figure 5 a shows, fluorescence emission of AGE products for different samples. Samples with higher incubation time with glucose have higher fluorescence emission. Figure $5 b$ is a cross section of Figure $5 a$, at fixed sixth week. This indicates a decrease in fluorometry parameter, as the laser irradiation energy dose increases.

\section{Discussion}

Catalase enzyme activity under glycation condition (in vitro) and in type 2 diabetes (in vivo) has been studied previously. ${ }^{5,24}$ Mechanisms involved in the prevention of catalase denaturation and the reduction of its activity under these effects (in vitro and in vivo fields) should be

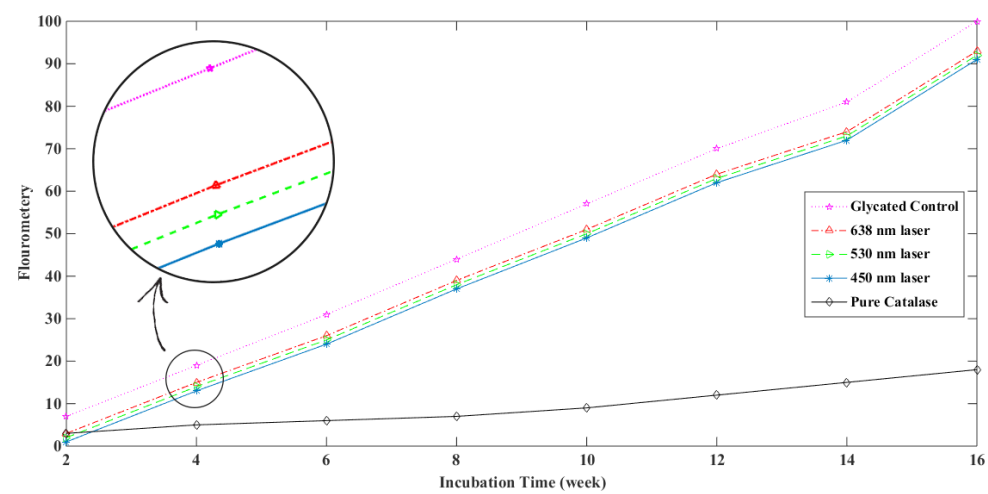

Figure 2. Fluorescence Emission Versus its Incubation Time (Weeks) for Different Laser Irradiation. Red, green, blue lines are the glycated catalase samples exposed to red $(638 \mathrm{~nm})$, green $(530 \mathrm{~nm})$ and blue $(450 \mathrm{~nm})$ laser irradiation at $0.1 \mathrm{~J} / \mathrm{cm}^{2}$ energy dose. Control groups are the glycated catalase samples which did not receive any irradiation. Pure catalase samples were not glycated and did not receive any irradiation (error $<0.06)$.

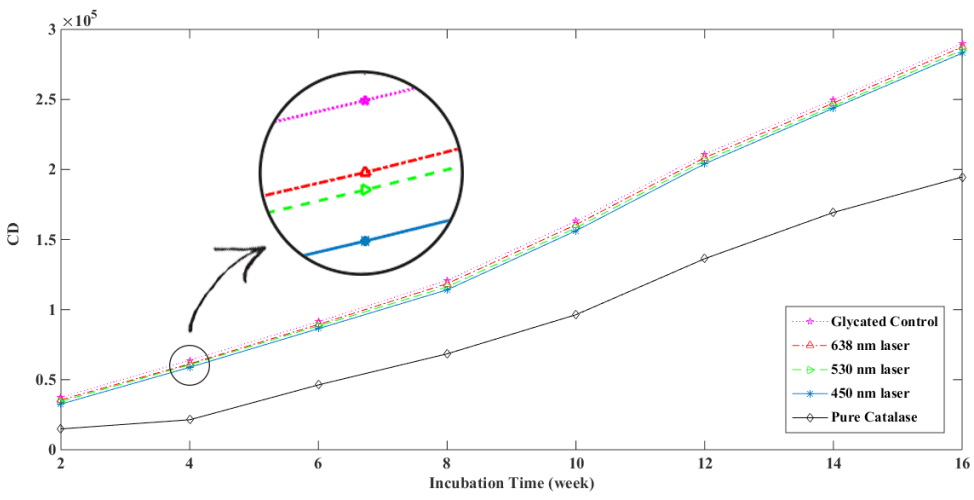

Figure 3. Catalase CD Versus its Incubation Time (Weeks) for Different Laser Irradiation. Red, green, blue lines are the glycated catalase samples exposed to red $(638 \mathrm{~nm})$, green $(530 \mathrm{~nm})$ and blue $(450 \mathrm{~nm})$ laser irradiation at $0.1 \mathrm{~J} / \mathrm{cm}^{2}$ energy dose. Control groups are the glycated catalase samples which did not receive any irradiation. Pure catalase samples were not glycated and did not receive any irradiation $($ error $<0.03)$. 

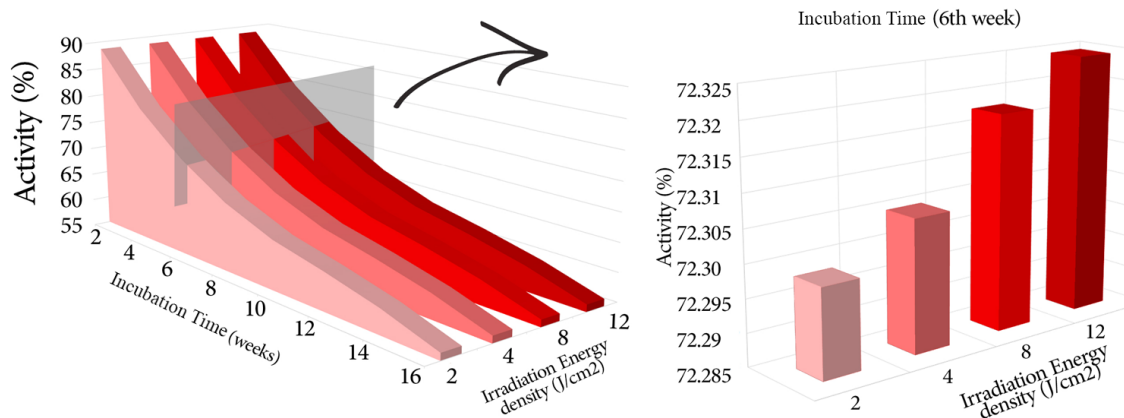

Figure 4. Activity of Glycated Catalase Versus Incubation Time (Week) and $905 \mathrm{~nm}$ Pulsed Laser Irradiation Energy Dose (2, 4, 8, 12 J/cm2). (a) Catalase activity for different energy doses $\left(2,4,8,12 \mathrm{~J} / \mathrm{cm}^{2}\right)$ of laser irradiation. The glycated samples had different incubation time $(2$ up to 16 weeks). (b) A cross section of graph part (a), samples with 6th week of incubation time, after receiving 2, 4, 8, $12 \mathrm{~J} / \mathrm{cm}^{2}$ energy dose of laser irradiations
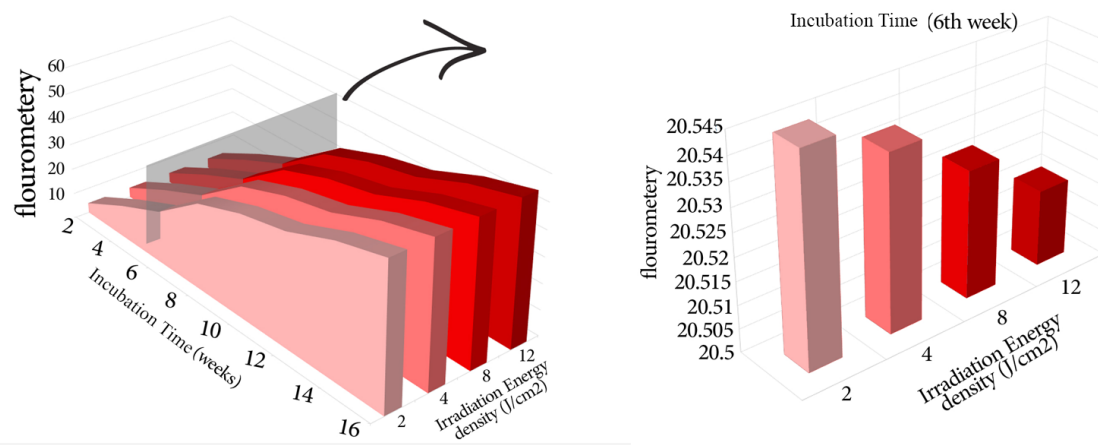

Figure 5. Fluorescence Emission of Glycated Catalase Versus Incubation Time (Week) and $905 \mathrm{~nm}$ Pulsed Laser Irradiation Energy Dose $\mathrm{J} / \mathrm{cm} 2)$ (a) Catalase fluorometry for different energy doses $\left(2,4,8,12 \mathrm{~J} / \mathrm{cm}^{2}\right)$ of laser irradiation. The glycated samples had different incubation time $(2$ up to 16 weeks). (b) A cross section of graph part (a), samples with 6 th week of incubation time, after receiving 2, 4, 8, $12 \mathrm{~J} / \mathrm{cm}^{2}$ energy dose of laser irradiations.

investigated. Nowadays complement theories which use multiple potential compounds or methods are noticeable. In the present study, we investigated the structure and the activity of glycated catalase exposed to laser irradiation. Laser irradiation such as LLLI is a convenient and attractive candidate for complement therapy, in order to reduce oxidative stress and to modify the activity of enzyme $^{39,40}$ even in diabetes condition. ${ }^{24,27}$ In one study, the influence of low-level GaAlAs laser irradiation at $904 \mathrm{~nm}$ for different doses on amylase activity was investigated experimentally. ${ }^{29}$ The results indicated that, for laser energy dosage under $0.1 \mathrm{~J} / \mathrm{cm}^{2}$ the enzymatic activity increased, while for energy dosage over $0.5 \mathrm{~J} /$ $\mathrm{cm}^{2}$, enzymatic activity decreased. Our experiments were performed on different samples and we had the same conclusion for all of them. We showed the positive alteration not only in the activity, but also in the structure of the glycated catalase. The structural results including $\mathrm{CD}$ and fluorometry data indicate, the shift of related quantities to normal level under laser irradiation. Like our previous work on glycated protein, ${ }^{32}$ fluorescence emission increased with glycation time. This is due to the higher amount of AGEs compounds in the samples. These alternations were adapted with activity alterations that were approached to natural level by laser. In the last part of our experiment, we focused on energy dosage of $0.1 \mathrm{~J} / \mathrm{cm}^{2}$, and investigated the effect of laser wavelength on catalase activity and its structure, including CD and fluoroscopy.

In the second part of our experiment, irradiation was performed by $100 \mathrm{~ns}$ pulsed IR laser (lambda $=905 \mathrm{~nm}$ ) with four different energy doses. Remember that in the first part of our experiment the power density, radiation time and spot area of radiation were kept constant and only the wavelength of laser was the variable. While, the second part of experiment (IR laser) the wavelength, laser power and pulse rate were kept constant and only the irradiation time was the variable. This effect of IR irradiation showed that, it was also correlated with the visible laser irradiation. Figure 4a shows catalase activity decreased by increasing glycation time. Fig $4 \mathrm{~b}$ indicates that for a fix glycation time, the activity of catalase increased by irradiation energy density.

Circular dichroism Figure 5a and fluorometry Figure 6a 
indicate their increase as glycation time. Figure $5 \mathrm{~b}$ circular dichroism and Figure $6 \mathrm{~b}$ fluorometry are both decreased versus irradiation energy density.

One of our experiments was uniform irradiation of catalase. For this purpose, we designed and made an aluminum cavity to make sure that the laser irradiation will be absorbed by catalase after multiple reflections inside the cavity.

\section{Conclusion}

We compared the effect of laser irradiation, with different wavelengths on glycated catalase and showed that the activity and fluorometry and CD of glycated catalase are changed by blue laser more than green and red lasers. Based on this study, laser irradiation with higher photon energy, has more impact on the activity and structure of catalase. In IR laser irradiation, we experienced an increase in activity as a function of irradiation dosage and also a decrease in CD and fluorometry.

\section{Ethical Considerations}

This investigation has been done on the pure laboratory materials such as catalase enzyme (purchased from SIGMA Co) and glucose powder (purchased from SIGMA Co) that does not need ethical approval. We didn't directly search about human or animals that need ethical document for ethical approval. Informed Consent of this investigation has been ordered by Physic Department of Sharif University of Technology.

\section{Conflict of Interests}

The authors declare no conflict of interest.

\section{Funding}

this study was supported by the Lasers and Medical Physics Lab of Sharif University of Technology and was not funded by any commercial company.

\section{Acknowledgments}

This project was supported by Sharif Applied Physics research center at Sharif University of Technology. Lasers were supplied and calibrated by Dr. Zandi Mehran, Laser and Neuroscience Specialist from International Faran Tech Co. Samples radiation were performed in Medical Laser Lab of Physics Department by Nafise Goli, Hedyeh Teymouri and Mahdi Aghaee.

\section{References}

1. Chance B, Sies H, Boveris A. Hydroperoxide metabolism in mammalian organs. Physiol Rev. 1979;59(3):527-605. doi: 10.1152/physrev.1979.59.3.527

2. Fehér J, Csomós G, Vereckei A. Free radical reactions in medicine. Springer Science \& Business Media; 2012.

3. Brownlee M. The pathological implications of protein glycation. Clin Invest Med. 1995;18(4):275-81.

4. Bourdon E, Loreau N, Blache D. Glucose and free radicals impair the antioxidant properties of serum albumin.
FASEB J. 1999;13(2):233-44.

5. Maritim A, Sanders a, Watkins rJ. Diabetes, oxidative stress, and antioxidants: a review. J Biochem Mol Toxicol. 2003;17(1):24-38. doi: 10.1002/jbt.10058

6. Kalousova M, Skrha J, Zima T. Advanced glycation endproducts and advanced oxidation protein products in patients with diabetes mellitus. Physiol Res. 2002;51(6):597604.

7. Yan SD, Schmidt AM, Anderson GM, Zhang J, Brett J, Zou YS, et al. Enhanced cellular oxidant stress by the interaction of advanced glycation end products with their receptors/ binding proteins. J Biol Chem. 1994;269(13):9889-97.

8. Mullarkey CJ, Edelstein D, Brownlee M. Free radical generation by early glycation products: a mechanism for accelerated atherogenesis in diabetes. Biochem Biophys Res Commun. 1990;173(3):932-9. 2176495

9. Baynes JW. Role of oxidative stress in development of complications in diabetes. Diabetes. 1991;40(4):405-12.

10. Baynes JW, Thorpe SR. Role of oxidative stress in diabetic complications: a new perspective on an old paradigm. Diabetes. 1999;48(1):1-9.

11. Choi M-S, Jeong MJ, Park YB, Kim SR, Jung UJ. The Leaf of Diospyros kaki Thumb Ameliorates Renal Oxidative Damage in Mice with Type 2 Diabetes. Prev Nutr Food Sci. 2016;21(4):378. doi: 10.3746/pnf.2016.21.4.378

12. Chen YP, Liu YJ, Wang XL, Ren ZY, Yue M. Effect of microwave and He-Ne laser on enzyme activity and biophoton emission of isatis indigotica fort. J Integr Plant Biol. 2005;47(7):849-55.

13. Sokolovic D, Djindjic B, Nikolic J, Bjelakovic G, Pavlovic D, Kocic $\mathrm{G}$, et al. Melatonin reduces oxidative stress induced by chronic exposure of microwave radiation from mobile phones in rat brain. J Radiat Res. 2008;49(6):579-86.

14. Horikoshi S, Nakamura K, Kawaguchi M, Kondo J, Serpone $\mathrm{N}$. Effect of microwave radiation on the activity of catalase. decomposition of hydrogen peroxide under microwave and conventional heating. RSC Adv. 2016;6(53):48237-44.

15. Sallam SM, Awad AM. Effect of static magnetic field on the electrical properties and enzymes function of rat liver. Romanian J Biophys. 2008;4:337-47.

16. Vojisavljevic V, Pirogova E, Cosic I, editors. Influence of electromagnetic radiation on enzyme kinetics. Engineering in Medicine and Biology Society, 2007 EMBS 2007 29th Annual International Conference of the IEEE; 2007: IEEE.

17. Fedoseyeva G, Karu T, Lyapunova T, Pomoshnikova N, Meissel M. The activation of yeast metabolism with $\mathrm{He}-\mathrm{Ne}$ laser radiations-II. Activity of enzymes of oxidative and phosphorous metabolism. Lasers Life Sci. 1988;2:147-54.

18. Karu T, Lyapunova T, Pomoshnikova N. The activation of yeast metabolism with $\mathrm{He}-\mathrm{Ne}$ laser radiation. IV. Relationship between the activity of catalase and stimulation of protein synthesis. Lasers Life Sci. 1993;5:251-7.

19. Denadai AS, Aydos RD, Silva IS, Olmedo L, Cardoso de Senna B, Kato da Silva B, et al. Acute effects of low-level laser therapy $(660 \mathrm{~nm})$ on oxidative stress levels in diabetic rats with skin wounds. $J$ Exp Ther Oncol. 2015;11:85-9.

20. Silva Macedo R, Peres Leal M, Braga TT, Barioni ÉD, de Oliveira Duro S, Ratto Tempestini Horliana AC, et al. Photobiomodulation Therapy Decreases Oxidative Stress in the Lung Tissue after Formaldehyde Exposure: Role of Oxidant/Antioxidant Enzymes. Mediators Inflamm. 
2016;2016. doi: 10.1155/2016/9303126

21. Chen H, Wang H, Li Y, Liu W, Wang C, Chen Z. Biological effects of low-level laser irradiation on umbilical cord mesenchymal stem cells. AIP Adv. 2016;6(4):045018.

22. Unnikrishna Pillai P, Padma N. Studies on the effect of laser radiation and other mutagens on plants. Cochin University of Science And Technology; 1998.

23. Simões A, Ganzerla E, Yamaguti PM, de Paula Eduardo C, Nicolau J. Effect of diode laser on enzymatic activity of parotid glands of diabetic rats. Lasers Med Sci. 2009;24(4):591-6. doi: 10.1007/s10103-008-0619-2

24. Simoes A, de Oliveira E, Campos L, Nicolau J. Ionic and histological studies of salivary glands in rats with diabetes and their glycemic state after laser irradiation. Photomed Laser Surg. 2009;27(6):877-83.

25. Ibuki FK, Simoes A, Nogueira FN. Antioxidant enzymatic defense in salivary glands of streptozotocin-induced diabetic rats: a temporal study. Cell Biochem Funct. 2010;28(6):503-8. doi: 10.1002/cbf.1683

26. Simoes A, Nogueira FN, de Paula Eduardo C, Nicolau J. Diode laser decreases the activity of catalase on submandibular glands of diabetic rats. Photomed Laser Surg. 2010;28(1):91-5.

27. Campos L, Nicolau J, Arana-Chavez VE, Simoes A. Effect of Laser Phototherapy on Enzymatic Activity of Salivary Glands of Hamsters Treated with 5-Fluorouracil. Photochem Photobiol. 2014;90(3):667-72. doi: 10.1111/ php. 12195

28. Simões A, Siqueira WL, Lamers ML, Santos MF, de Paula Eduardo C, Nicolau J. Laser phototherapy effect on protein metabolism parameters of rat salivary glands. Lasers Med Sci. 2009;24(2):202-8. doi: 10.1007/s10103-008-0548-0

29. Da Silva NS, Potrich JW. Effect of GaAlAs laser irradiation on enzyme activity. Photomed Laser Surg. 2010;28(3):4314. doi: $10.1089 /$ pho. 2008.2410

30. Shaklai N, Garlick RL, Bunn HF. Nonenzymatic glycosylation of human serum albumin alters its conformation and function. J Biol Chem. 1984;259(6):38127 .

31. Jafarnejad A, Bathaie S, Nakhjavani M, Hassan M, Banasadegh S. The improvement effect of L-Lys as a chemical chaperone on STZ-induced diabetic rats, protein structure and function. Diabetes Metab Res Rev. 2008;24(1):64-73. doi: 10.1002/dmrr.769

32. Mirmiranpour H, Bathaie SZ, Khaghani S, Nakhjavani M, Kebriaeezadeh A. Investigation of the mechanism (s) involved in decreasing increased fibrinogen activity in hyperglycemic conditions using L-lysine supplementation. Thromb Res. 2012;130(3):e13-e9. doi: 10.1016/j. thromres.2012.04.010

33. Coussons PJ, Jacoby J, McKay A, Kelly SM, Price NC, Hunt JV. Glucose modification of human serum albumin: a structural study. Free Radic Biol Med. 1997;22(7):1217-27.

34. Nelson SK, Bose SK, Grunwald GK, Myhill P, McCord JM. The induction of human superoxide dismutase and catalase in vivo: a fundamentally new approach to antioxidant therapy. Free Radic Biol Med. 2006;40(2):341-7. doi: $\quad$ 10.1016/j.freeradbiomed.2005.08.043

35. Ogino $\mathrm{T}$, Okada $\mathrm{S}$. Oxidative damage of bovine serum albumin and other enzyme proteins by iron-chelate complexes. Biochimica et Biophysica Acta (BBA)-General Subjects. 1995;1245(3):359-65.

36. Gopalkrishnapillai B, Nadanathangam V, Karmakar N, Anand S, Misra A. Evaluation of autofluorescent property of hemoglobin-advanced glycation end product as a longterm glycemic index of diabetes. Diabetes. 2003;52(4):10416. PMID: 12663478

37. Jackson DY, King DS, Chmielewski J, Singh S, Schultz PG. General approach to the synthesis of short. alpha.-helical peptides. J Am Chem Soc. 1991;113(24):9391-2.

38. Chapra SC, Canale RP. Numerical methods for engineers. New York: McGraw-Hill; 1998.

39. Silveira PCL, Silva LA, Freitas TP, Latini A, Pinho RA. Effects of low-power laser irradiation (LPLI) at different wavelengths and doses on oxidative stress and fibrogenesis parameters in an animal model of wound healing. Lasers Med Sci. 2011;26(1):125-31. doi: 10.1007/s10103-0100839-0

40. Guaraldo SA, Serra AJ, Amadio EM, Antônio EL, Silva F, Portes LA, et al. The effect of low-level laser therapy on oxidative stress and functional fitness in aged rats subjected to swimming: an aerobic exercise. Lasers Med Sci. 2016;31(5):833-40. doi: 10.1007/s10103-016-1882-2 